\title{
HEALTH CARE REGULATION: IMPACT ON THE SUPPLY OF OUTPATIENT SERVICES IN THE CZECH REPUBLIC
}

\author{
Martin DLOUHÝ*
}

\begin{abstract}
:
The objective of this paper is to evaluate the impact of regulatory policy on the supply of outpatient services and on their geographical distribution in the Czech Republic. The analysis of regulatory policy is based on the review of literature. Trends and regional distribution were analysed quantitatively on the data for the period of 1990 to 2002. Regulation introduced in 1997 led to a financial stability of the health sector, but it did not have a great impact on the level and distribution of outpatient services. Regulatory policy can be seen as a failure if one assumes that improved quality, effectiveness, and efficiency are the objectives of the health system. The supply of outpatient services is unevenly distributed. For example, one-quarter of outpatient services in psychiatry is concentrated in the capital.
\end{abstract}

Keywords: regulation, health care, outpatient services, inequality, Gini coefficient, Robin Hood index

JEL Classification: I180, D630, H000.

\section{Introduction}

The health system of the Czech Republic underwent radical changes during the 1990s. After the overthrow of the communist government in 1989, an opportunity window for wide social reforms, including health reforms, has opened. The tax-financed, national health service was seen as a health system that offered a low quality of care, poor consumer satisfaction, and economic inefficiency. Radical health reform was proposed and launched very quickly. The tax-finance system was replaced by the universal health insurance in 1993. As part of the reform, outpatient services, which had been to a large extent privatized, began to be paid on a fee-for-service basis. The market-like incentives have changed behaviour within the medical profession. Unrestricted growth in the number of practices and unregulated volume of services proved quickly to be financially unsustainable. After a few unsuccessful efforts to stabilize the health sector, a tight budgeting replaced the openended system in 1997. This change provided us with a unique opportunity to analy-

*) University of Economics, 4, W. Churchill Sq., CZ - 13067 Prague 3 (e-mail: dlouhy@vse.cz).

${ }^{\star *}$ ) This project was supported by the NIH Research Grant No. D43 TW05810, funded by the Fogarty International Center and the National Institute of Mental Health. 
se the impact of changes in the regulatory framework on the supply of outpatient services. The first objective is to explore whether regulation has stopped the growth in the supply of outpatient services.

In the public health system, a fair geographical distribution of services should be one of the health policy objectives. Therefore, the second objective is to explore whether regulation led to a more equal geographical distribution of outpatient services. The empirical findings show that the unequal distribution of service is a problem in developing as well as developed countries (e.g., Chang and Halfon, 1997; Gravelle and Sutton, 1998; Johnston and Wilkinson, 2001).

In this study, I begin with the description of data and methods used. The following part is analytical and is divided into four subsections. The first subsection deals with the analysis of regulatory policy in the Czech Republic between 1990 and 2002. It is mainly based on the review of literature. The second subsection analyses the supply of outpatient services at the national level. The third subsection discusses the regional distribution of outpatient services. In the fourth subsection, outpatient psychiatric care is discussed, which provides an example of development in one medical specialty. I summarize the findings in the conclusion.

\section{Data and Methods}

The analysis of regulatory policy is based on the review of these studies: Potuček (1991); Massaro, Němec and Kalman (1994); National Economic Research Associates (1996); Beckmann and Němec (1997); Jaroš and Kalina (1998); Dlouhý and Mariel (1999); Health Care System in Transition - the Czech Republic (World Health Organization, 2000); OECD Economic Surveys - the Czech Republic (OECD, 2003) and Efficient Health Care System which Respects Human Dignity: Draft Health Care Policy Concept for the Czech Republic for 2004 - 2009 (Ministry of Health of the Czech Republic, 2004). All of these studies and documents analyse the Czech health reform as a whole, and outpatient services are addressed to a different degree. Because the contents of the studies highly overlap, I do not quote them in the text if it is not necessary. Finally, the health insurance legislation of the Czech Republic served as a source of information.

The quantitative analysis includes the analysis of data on the national level and the analysis of the regional distribution. The inequality of geographical distribution is measured by the absolute range, the relative range, the Gini coefficient, and the Robin Hood index. The absolute and relative ranges are simple indicators based on the extreme values only. The Gini coefficient and Robin Hood index take into account all observations. The Gini coefficient is a measure of the inequality based on the Lorenz curve. The Lorenz curve is a cumulative frequency curve that compares the empirical distribution of a specific resource with the uniform (egalitarian) distribution that represents perfect equality. The Gini coefficient ranges from 0 , in the case of perfect equality, to 1 , in the case of perfect inequality. The Robin Hood index measures what proportion of resources has to be moved from areas with above-average provision to areas with below-average provision to achieve equal distribution. The Robin Hood index is not able to register transfers between areas if both lie below or above the national mean. Such reallocations would be undervalued by the Robin Hood index. However, its main advantage over the Gini coefficient is its clear interpretation for wider health policy public.

I used only the population as a measure of need, although some authors have used the crude death rate for this purpose. The decision to use the population as a measure of need was based on our previous study (see Dlouhý, Zelený and Lepič, 2001) in which we sought to explain the differences in the distribution of general 
practitioners (GPs) among the districts of the Czech Republic in 1999, using various health and socioeconomic indicators. The correlation coefficient of the number of GPs per capita with the crude death rate showed no correlation $(r=0.0137, p>$ 0.05). There was also no correlation between the number of GP's visits per capita and the crude death rate $(r=0.0055, p>0.05)$. These findings question the use of the crude death rate as a proxy variable of the need for outpatient services, at least under Czech conditions.

For administrative and statistical purposes, the country is divided into 14 regions and 77 districts. There were, however, limitations to the data on geographical areas, as some services provided by physicians in one area are consumed by patients from other geographical areas. I preferred, therefore, a region to a district for our unit of analysis in order to reduce this problem. For some calculations, I put together two regions, the city of Prague and Central Bohemian region, where the flow of patients from the suburban area to Prague was assumed to be relatively high. All the data come from the Institute of Health Information and Statistics of the Czech Republic. The supply of outpatient services is measured by the number of outpatient physicians of all medical specialties (including dentists) in full-time equivalents. The number of outpatient physicians includes physicians in independent practices as well as those from outpatient hospital departments, but excludes roughly $3 \%$ of outpatient physicians, who are under the administration of the Ministries of Defense, Justice, Interior, and Transport. I treat all physicians as having contracts with public health insurance companies, which is not necessarily the case; however, it can be assumed that the number of physicians with no public contract is negligible in a country with no private health insurance. The national data cover the period between 1990 and 2002. The new regional administration of 14 regions has existed from the year 2000, but fortunately, the regional data were available back to 1996, which is by coincidence the last year of fee-for-service medicine. Thus, I was able to make the analysis at the regional level for the period between 1996 and 2002.

\section{An alys is}

\subsection{Regulatory Policy (1990 - 2000)}

In the post-revolution period, from 1990 to 1992, profound health reform proposals were prepared. During that period the command-and-control system was rapidly removed without an introduction of the new regulatory mechanisms. Patients gained a free choice of providers, which had been restricted under the communist regime. At that time, the health sector had been underfinanced, and the share of health expenditures in the gross domestic product was $5.4 \%$ in 1992 . Health providers were not privatized yet, and the fee-for-service reimbursement was under development. Hence, the economic behaviour of actors began to manifest itself first of all in the political lobbying in order to influence the design of health reform, but could not yet do so in the economic practice. The Medical Chamber was founded by the Act No. 220/1991; the Act No. 160/1992 enabled setting up of private practices; and the Act No. 550/1991, 551/1991, 280/1992, and 592/1992 set up the necessary health insurance legislation. The Act No. 551/1991 on the General Health Insurance Company of the Czech Republic introduced free contracting for providers which meant that if a provider asked for a contract, it had to be accepted by this company in the years 1992 and 1993. This rule, which was to ease the privatization of health services, caused unregulated expansion of services.

The new epoch began in January 1993 when the universal health insurance fully replaced the tax-financed system. Health expenditures jumped to $7.3 \%$ of the 
gross domestic product in 1993. The separation of purchasing and provision functions was introduced. The purchasing function was placed into the hands of newly established health insurance companies, which are autonomous public organizations that collect insurance contributions and purchase services from providers. Due to financial problems, 18 smaller insurance companies established between 1993 and 1997 had to be abolished (see Jaroš and Kalina, 1998). Nine health insurance companies (January 2005) now compete for enrollees. The health insurance market is dominated by the General Health Insurance Company of the Czech Republic, which covers around $70 \%$ of population (2004).

At the beginning of the 1990s, a mass privatization of providers was seen as the main remedy for inefficiency. Currently, the majority of primary and specialized outpatient care providers are private, mostly established as independent practices. On the other hand, the privatization of hospitals was stopped and the majority of hospitals are now under the control of regions and municipalities. Hospitals run their own outpatient departments, so there are two networks of outpatient services. Operating under fee-for-service reimbursement, and with no problem in securing contracts from health insurance companies, hospitals have tried to expand their outpatient services. Such a strategy postponed a financial crisis in the hospital sector by gaining additional income from outpatient and laboratory services with low marginal costs.

In the newly established universal health insurance system, services were paid by fee-for-service with no co-payments and no gate-keeping. Services were reimbursed according to the List of Health Services, which sets the relative point values for each service, whereas the monetary value of point had initially been set by the individual insurance company. The point value of a given service is based on the estimated time and material costs, but also on the lobbying power of an individual medical specialty. With hundreds of services, it is difficult to avoid bias, so disputes between medical specialties and between inpatient and outpatient sectors arose. Drugs were reimbursed according to the price list. Since drugs must be paid, the production of more services with more prescriptions leads to a lower total reimbursement for providers. Later, the system of reference prices according to therapeutic categories came into operation. Because the difference between a reference price and drug price (if the latter is higher) has to be paid out-of-pocket, physicians prescribe more carefully so as not to lose patients.

It should be noted that the market-like incentives have changed behaviour within the medical profession. The initial data from health insurance companies showed that privatized physicians generated greater volume and consumed more resources than those who stayed to work as salaried public employees (see Massaro, Němec, and Kalman, 1994). The weak regulation of service volume and unregulated contracting brought about the over-utilization of services and the building of new excessive capacities, and ultimately threatened the economic stability of the health sector. As a defense, health insurance companies gradually decreased the monetary value of point. The value of point was set according to the financial situation of the companies, irrespective of the real cost of service. Decreasing the fees simply transferred financial problems back to the providers and did not address the wider systemic problems. The funds also delayed reimbursement a few weeks or months, which again solved their financial problems by shifting them onto providers. Later, the funds adopted a strategy of dividing the total expenditures into separate expenditure categories according to the type of providers (e.g. general practitioners, specialized outpatient services, inpatient services, and so on).

In July 1997, a new version of the List of Health Services was published. Providers argued that their fees were lower than the real costs, but health insurance companies countered that they would not be able to pay the fees. In that situation, the 
List of Health Services was rejected and the budgets for individual providers were agreed upon as a provisional measure to avoid a financial crisis in the health sector. Nobody expected that the provisional budget regulation would become a permanent strategy of cost containment. In July 1997, the open-ended system was suddenly replaced by tight regulation. The changes in the reimbursement system, which started the third period of health regulation, made the essential modification of economic incentives for health providers. The end of the fee-for-service system removed the financial incentives for over-utilization; instead, the motivations to minimize the volume and cost of services became an economically rational behaviour of physicians. As another step for cost containment, negotiations between the health insurance companies and the organized groups of providers at the national level were introduced by the Act No. 48/1997. The objective of negotiation is to set fees and percentage growths of expenditure ceilings. The negotiated reimbursement system may be changed every six months according to negotiation cycles. In case that negotiations between insurance companies and health providers are not successful, the national government is obliged to make decisions about reimbursement for the next six months.

General practitioners are now (2004) paid by capitation, with a combination of fee-for-service for certain services (e.g. immunization). Specialists are still paid by the fee-for-service system, but with tight time limits and expenditure ceilings, which, in practice, mean the budgeting of specialized outpatient services. The gate-keeping function of general practitioners or the co-payments at the point of service is not enforced, so a patient can contact a specialist directly without a referral. Such behaviour is, however, much harder, because specialists try to limit the number of patients in order to stay within the time limits and expenditure ceilings. The negative results of budgeting are waiting lists and possible corruption related to these lists. The introduction of some co-payments, regulating the excessive demand and generating additional resources, was highly recommended (see OECD, 2003). Dental services are reimbursed according to the price list and represent the least regulated sector. Dentists have been able to stay within the total budget for dental services, which may be related to the facts that dentists earn a part of their incomes from out-of-pocket payments for above-standard services and materials and that demand for dental care is likely to be self-limited, especially for services with high co-payments. The reimbursement of hospital services is based on the simple per-case system with expenditure ceilings, which, in reality, means historical budgets. Outpatient services delivered in hospital are considered as a part of the hospital budget and paid by fixed sums. The different regulatory conditions for the independent and the hospital-based outpatient physicians create conflicts between these two groups of physicians.

\section{2 The Supply of Outpatient Services at the National Level}

In 1990, there were $22,424.9$ outpatient physicians (in full-time equivalents) in total and 21.7 per 10,000 inhabitants. The share of primary-care physicians (general practitioners, dentists and primary-care gynecologists) was $59 \%$. As discussed in the previous section, since 1990, we can identify three regulatory periods: the post-revolution period between 1990 and 1992, during which the nationalized health system was removed and health reform prepared; the period of fee-for service medicine, between 1993 and 1996; and the period of budget-oriented cost containment, between 1997 and 2002, which still continues (as of January 2005). Figure 1 illustrates the trends in the total supply of outpatient physicians and in the number of outpatient contacts per capita. First, the relative number of physicians decreased to 
19.0 per 10,000 in 1992 , and the number of contacts decreased slightly, too. In the next period, after introduction of health insurance, a relative increase of $30 \%$ in the number of physicians between 1992 and 1996 coincides with the period of fee-forservice medicine and unregulated contracting. The number of contacts per capita also grew and reached the value of 15 contacts per capita yearly in 2002 . However, that indicator says little about the number and the type of services provided during the contact. Nor does this indicator say whether there was a shift from lower- to higher-paid services. The observed trends may suggest that unrestricted contracting played a more important role in the supplier-induced demand than did openended fee-for-service.

Figure 1

The Number of Outpatient Physicians and the Number of Outpatient Contacts per Capita $(1990=100$, in \%)

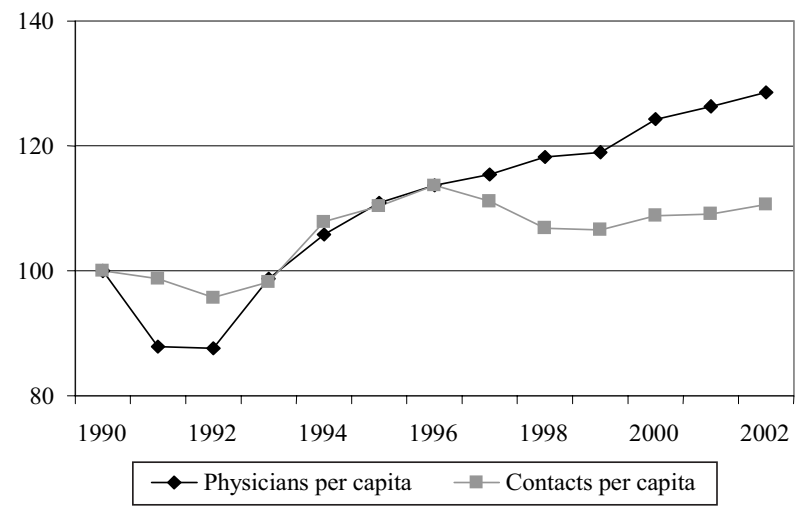

In July 1997, the budgets at both the national level and provider's level were introduced. In the last year of fee-for-service medicine - in 1996, there were 25,436 outpatient physicians (in full-time equivalents). Despite tight financial regulation and the first attempts at selective contracting, that number of physicians grew to 27,666 in the year 2002. The share of primary-care physicians (general practitioners, dentists and primary care gynecologists) in the total number of outpatient physicians dropped from $59 \%$ in 1990 to $55 \%$ in 1996 and to $51 \%$ in 2002 . This drop shows that the specialists were those who had driven the growth in the number of physicians. In total, there was an increase of $8.8 \%$ in the absolute number of physicians, and of $10.0 \%$ in the relative number if the population decline is taken into account. These figures mean that the outpatient sector is constantly growing despite the regulation launched in 1997. All studies I have reviewed share the same view that there is an excessive capacity of outpatient specialists in the country and they recommend that the supply of services should be reduced. Facing these facts, one may deem regulation unsuccessful. After 12 years, the Czechs have $28.2 \%$ more outpatient physicians per capita at their disposal, and the number of contacts with these doctors increased by $10.7 \%$. But there is no evidence that so many outpatient physicians are really needed. Because the number of physicians is increasing and the number of contacts has roughly been stable since 1996, one can conclude that there has been a continuous loss of productivity in the outpatient sector (see Figure 1). 


\section{3 Regional Distribution}

The development in the relative numbers of outpatient physicians between years 1996 and 2002 is shown in Table 1. Because some services provided by physicians in one region are consumed by patients from other regions, I decided, for the purpose of calculations, to put together the city of Prague and the region of Central Bohemia, where the flow of patients from the neighbouring suburban area of Central Bohemia to Prague was likely to be high. Even after that aggregation, the relative numbers of physicians were high for the united region of Prague and Central Bohemia, if compared with those for the rest of the country. The capital, Prague, holds an exceptional position with the far highest supply of services per capita. In spite of an already high supply of services, the city witnessed a further increase of $14.3 \%$ in physician-to-population ratio during the period of 1996 to 2002. Prague absorbed $21.2 \%$ of the 2,231 new outpatient physicians (in full-time equivalents). Although the city of Prague faces a declining share in the total country population, from $11.7 \%$ in 1996 to $11.4 \%$ in 2002 , it has increased its share in the total supply of outpatient physicians from $19.2 \%$ to $19.7 \%$.

Table 1

Regional Distribution of Outpatient Physicians

\begin{tabular}{|l|r|r|r|r|c|}
\hline \multirow{2}{*}{ Region } & \multicolumn{2}{|c|}{ Population } & \multicolumn{3}{c|}{ Physicians per 10,000 } \\
\cline { 2 - 6 } & \multicolumn{1}{|c|}{1996} & \multicolumn{1}{c|}{2002} & 1996 & 2002 & Change in \% \\
\hline Prague & $1,207,299$ & $1,158,800$ & 40.40 & 46.16 & 14.3 \\
\hline Středočeský) & $1,106,013$ & $1,125,735$ & 19.68 & 21.24 & 7.9 \\
\hline Jihočeský & 626,618 & 624,778 & 24.21 & 25.08 & 3.6 \\
\hline Plzeňský & 554,904 & 549,369 & 25.68 & 28.38 & 10.5 \\
\hline Karlovarský & 305,088 & 303,761 & 20.40 & 22.64 & 11.0 \\
\hline Ústecký & 825,188 & 819,442 & 20.26 & 22.44 & 10.8 \\
\hline Liberecký & 429,076 & 427,418 & 21.18 & 22.78 & 7.6 \\
\hline Královéhradecký & 553,697 & 548,698 & 25.79 & 28.15 & 9.1 \\
\hline Pardubický & 509,893 & 506,849 & 20.83 & 23.94 & 14.9 \\
\hline Vysočina & 522,969 & 517,959 & 20.20 & 22.05 & 9.2 \\
\hline Jihomoravský & $1,140,427$ & $1,122,759$ & 27.18 & 29.07 & 7.0 \\
\hline Olomoucký & 645,419 & 637,401 & 23.83 & 26.28 & 10.3 \\
\hline Zlínský & 600,303 & 593,458 & 21.39 & 23.56 & 10.2 \\
\hline Moravskoslezský & $1,288,459$ & $1,264,347$ & 21.49 & 24.21 & 12.7 \\
\hline (Prague + Středočeský) & $2,313,312$ & $2,284,535$ & 30.49 & 33.88 & 11.1 \\
\hline Czech Republic & $10,315,353$ & $10,200,774$ & 24.66 & 27.12 & 10.0 \\
\hline
\end{tabular}

*) i.e. Central Bohemia

For the overall measurement of inequality, I used four measures of inequality and investigated two alternatives with 14 and 13 regions (if Prague and Central Bohemia are united into 1 region). Regions of Prague and of Central Bohemia are two extreme cases, so the alternative with 13 regions necessarily estimates a lower level of inequality. The first two inequality measures, the absolute range and the rela- 
tive range, indicate, in both alternatives, a more unequal distribution in 2002 than that in 1996 (see Table 2). The Gini coefficient and Robin Hood index show that the overall distribution of services is practically constant. The alternative with 14 regions indicates a very slight worsening, whereas the second one evidences a slight improvement. To sum up, the indicators of distribution did not demonstrate any real impact of regulation on the equality of distribution, and above all, on the oversupply of outpatient services in Prague. A bad message is that there is signal that the growth of outpatient services and the trend towards their centralization in the capital will reverse in the future.

Table 2

The Inequality of Regional Distribution

\begin{tabular}{|l|c|c|c|c|}
\hline \multirow{2}{*}{ Inequality Measure } & \multicolumn{2}{|c|}{14 regions } & \multicolumn{2}{c|}{13 regions } \\
\cline { 2 - 5 } & 1996 & 2002 & 1996 & 2002 \\
\hline Absolute range & 20.72 & 24.93 & 10.29 & 11.83 \\
\hline Relative range & 0.84 & 0.92 & 0.42 & 0.44 \\
\hline Robin Hood index (in \%) & 9.07 & 9.22 & 6.90 & 6.83 \\
\hline Gini coefficient & 0.1287 & 0.1319 & 0.0940 & 0.0933 \\
\hline
\end{tabular}

The expansion of outpatient services can be a positive development in the case that outpatient services replace inpatient services. Indeed, the number of beds in acute-care hospitals per capita felt by $10 \%$ during the period between 1996 and 2002. At the regional level, the picture is different (see Figure 2). The correlation between the relative change in the number of outpatient physicians and that in the number of beds in acute-care hospitals is low $(r=0.16, p>0.05)$, so it is not true that a higher reduction of hospital beds in a region is associated with a higher increase of outpatient services. There is surely some substitution between inpatient and outpatient services, but it does not seem to be a controlled health reform pro-

Figure 2

Relative Changes in the Number of Hospital Beds and the Number of Outpatient Physicians $(1996-2002$, in \%)

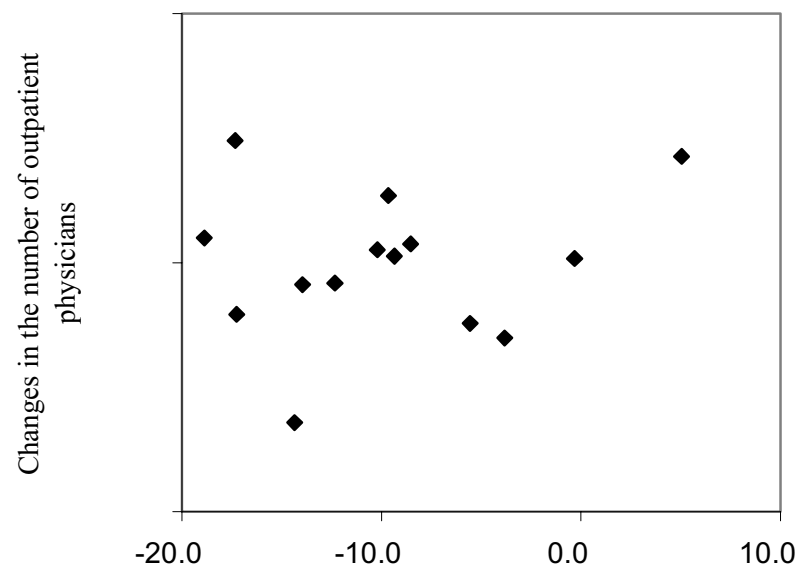

Changes in the number of hospital beds 
cess, nor it is related to any policy addressing the inequality of geographical distribution. Again, the development in Prague is completely different from that of the rest of the country. In 2002, the city had $5 \%$ more beds per capita than in 1996, whereas all other regions reduced their capacities.

\section{4 Outpatient Psychiatric Services}

I have thus investigated the developments in the total supply of outpatient services, regardless of the type of medical specialty. The total numbers, however, may hide the great variability among the medical specialties. Here, I aim to explore the development in psychiatry as one selected medical specialty. There were 418.0 psychiatrists in 1990 (in full-time equivalents); 501.2 in 1996; and 582.8 in 2002. The growth rate of the number of psychiatrists was $19.9 \%$ between 1990 and 1996; $16.3 \%$ between 1996 and 2002; and 39.4\% for the entire period between 1990 and 2002. These are much higher rates than the average rates for all outpatient services, which were $13.4 \%$ between 1990 and 1996, $8.8 \%$ between 1996 and 2002, and $23.4 \%$ for the entire period between 1990 and 2002. The number of beds in both the psychiatric units of general hospitals and the specialized psychiatric hospitals was reduced by one fifth between 1990 and 2002. Such a trend is in accord with the process of deinstitutionalization of mental health care. The results from the application of measures of inequality on the 2002 data were as follows: the relative range was 1.64, the Robin Hood index was $16.96 \%$, and the Gini coefficient was 0.220 . These numbers imply a greater inequality in the distribution of outpatient psychiatric services than that of all outpatient services. Psychiatry is extremely concentrated in the city of Prague, where $25.1 \%$ of psychiatric practices are located. There are 12.63 psychiatrists per 100,000 in Prague, but only 3.24 psychiatrics per 100,000 in the Zlínský region. The difference of that magnitude cannot be explained by the objective needs of population and could be interpreted as a failure of contracting policy in this type of services. This difference means that the process of deinstitutionalization will affect mental health patients differently in regions with a high supply of outpatient psychiatric services and in regions with a low supply of such services.

\section{Conclusion}

I have not found evidence that regulation stopped the growth of outpatient services and led to a better geographical distribution. Although the expansion of outpatient services could be a desired result of substitution of inpatient care, the data do not show it is a controlled process. This analysis, albeit limited, questions the implementation of the active purchasing role of health insurance companies. Rather, it seems that regulation has only petrified the health sector, giving the illusion of financial stability. However, latent problems manifest themselves regularly and are solved by ad hoc subsidies from the national budget. There are two parallel networks of specialized outpatient services, with the possibility that they double one another instead of complementing each other. The supply of outpatient services is high in Prague in comparison to the levels in other regions of the country. In psychiatry, for example, one quarter of the supply is concentrated in the capital. Future regulatory policy should be targeted to the heart of the country - the city of Prague.

The reviewed studies conclude that the combination of the open-ended fee-forservice reimbursement, the lack of active contracting policy, and the privatization of services inevitably leads to serious financial problems. It may appear to be a paradox, but the privatization process needed strong governmental control and adequa- 
te time for all the actors in the health system (providers, health insurance companies, as well as government itself) to understand the nature of privatization and regulation of privatized providers. Fee-for-service medicine and the lack of contracting policy have brought about many problems not only in the outpatient services, but also in other parts of the health system. Tight budgeting plausibly just hid these acute problems by creating an appearance of a financial balance, and postponed the real solutions of these problems. The introduction of some co-payments, regulating the excessive demand and generating additional resources, was highly recommended (see OECD, 2003), but this was rejected by the social democratic government (e.g. Ministry of Health of the Czech Republic, 2004). The design of incentives in the reimbursement system and the active, need-based purchasing are what matters.

References

Beckmann, M., Němec, J. (1997), "Health Care Systems in Transition in Eastern Europe: The Czech Case," in Altenstetter, C., Björkmann, J. W., eds., Health Policy Reform, National Variations and Globalization. New York: St. Martin's Press, pp. 314-330.

Chang, R. K., Halfon, N. (1997), "Geographic Distribution of Pediatricians in the United States: An Analysis of the Fifty States and the Washington." Pediatrics, 100(2), pp. 172-179.

Dlouhý, M., Mariel, P. (1999), "La Sanidad en la Republica Checa despues de nueve anos de democracia." Osasunkaria: revista vasca de salud publica y gestion sanitaria, 17, pp. 23-27.

Dlouhý, M., Zelený, M., Lepič, M. (2001), "Geographical Differences in Distribution of General Practitioners in the Czech Republic" (in Czech). Zdravotni politika a ekonomika, 2, pp. 3-17.

Gravelle, H., Sutton, M. (1998), "Trends in Geographical Inequalities in Provision of General Practitioners in England and Wales." Lancet, 352 (9144), pp. 1910.

Jaroš, J., Kalina, K. (1998), "Czech Health Care System: Delivery and Financing." Prague, Czech Association for Health Services Research.

Johnston, G., Wilkinson, D. (2001), "Increasingly Inequitable Distribution of General Practitioners in Australia, 1986-96." Australian and New Zealand Journal of Public Health, 25 (1), pp. 66-70.

Massaro, T. A., Němec, J., Kalman, I. (1994), "Health System Reform in the Czech Republic. Policy Lessons from the Initial Experience of the General Health Insurance Company." JAMA, 271(23), pp.1870-1874.

Ministry of Health (2004), "Efficient Health Care System which Respects Human Dignity: Draft Health Care Policy Concept for the Czech Republic for 2004 - 2009." Prague, Ministry of Health of the Czech Republic.

NERA (1996), "The Health Care System in the Czech Republic." London, National Economic Research Associates.

OECD (2003), "OECD Economic Surveys: The Czech Republic." Paris, Organization for Economic Cooperation and Development.

Potůček, M. (1991), "The Health Care Reform in Czechoslovakia after 17 November 1989." Journal of Public Health Medicine, 13 (4), pp. 290-294.

WHO (2000), "Health Care Systems in Transition: The Czech Republic." Copenhagen, World Health Organization, European Observatory on Health Care Systems. 